\title{
Comparison of chemotherapy plus bevacizumab vs. chemotherapy alone as third-line treatment or beyond for advanced non-small cell lung cancer: A propensity score-matched analysis
}

\author{
BINBIN HU ${ }^{1}$, XIAOJUAN ZHOU ${ }^{1}$, YONGMEI LIU ${ }^{1}$, QIAN LI $^{2}$, \\ MENGMENG XIANG $^{2}$, BINGWEN ZOU ${ }^{1}$, FENG PENG ${ }^{1}$, MEIJUAN HUANG ${ }^{1}$, YOULING GONG ${ }^{1}$, \\ JIANG ZHU ${ }^{1}$, YONGSHENG WANG ${ }^{1}$, LI REN ${ }^{1}$, YONG XU ${ }^{1}$, YAN ZHANG ${ }^{1}$, YANYING LI ${ }^{1}$, MIN YU ${ }^{1}$, \\ JIANXIN XUE ${ }^{1}$, LEI DENG ${ }^{1}$, JIN WANG $^{1}$, ZHENYU DING $^{1}$ and YOU LU ${ }^{1}$ \\ ${ }^{1}$ Department of Thoracic Oncology, West China Hospital; ${ }^{2}$ West China School of Medicine, \\ Sichuan University, Chengdu, Sichuan 610041, P.R. China
}

Received March 14, 2017; Accepted December 5, 2017

DOI: $10.3892 / 01.2018 .8064$

\begin{abstract}
The addition of bevacizumab to chemotherapy has demonstrated efficacy as a first-line treatment for non-small cell lung cancer (NSCLC). Whether this combination is effective as a salvage treatment for patients with NSCLC remains unclear. The present retrospective study was designed to compare the efficacy and safety of chemotherapy plus bevacizumab with chemotherapy alone as a third-line, or continuing, treatment for patients with NSCLC. Between January 2011 and June 2016, a total of 38 patients with stage IV NSCLC who had received chemotherapy plus bevacizumab subsequent to failure of $\geq 2$ prior regimens were matched with 38 patients who had received chemotherapy alone using propensity score matching from a dataset of 165 patients. The variables that were analyzed included age, sex, smoking history, histology, epithelial growth factor receptor mutation status, number of prior regimens and type of chemotherapy regimen. Univariate and multivariate analyses were used to evaluate the prognostic factors for survival outcomes and tumor response, and toxicity analyses were performed. The objective response rate (ORR) and disease control rate (DCR) were improved in patients who underwent chemotherapy-bevacizumab treatment compared with chemotherapy alone (ORR, 23.7 vs. 5.3\%, $\mathrm{P}<0.001$; DCR, 65.8 vs. $31.6 \%, \mathrm{P}<0.001)$. Progression-freesurvivalwasprolongedinthechemotherapy-bevacizumab group compared with the chemotherapy-alone group (median, 3.9 vs. 2.2 months; HR, 0.54; 95\% CI, 0.32-0.89, $\mathrm{P}=0.014)$. Incidence of $\geq$ grade 3 adverse events was low and similar across the groups. The combination of chemotherapy
\end{abstract}

Correspondence to: Professor You Lu, Department of Thoracic Oncology, West China Hospital, Sichuan University, 37 Guoxue Alley, Chengdu, Sichuan 610041, P.R. China

E-mail:radyoulu@hotmail.com

Key words: non-small cell lung cancer, chemotherapy, bevacizumab, efficacy, safety and bevacizumab is a potentially effective and safe alternative salvage treatment for patients with NSCLC who have not received bevacizumab treatment previously.

\section{Introduction}

Lung cancer is the leading cause of cancer-associated mortalities in China (1). Non-small cell lung cancer (NSCLC) accounts for $80 \%$ of all cases of lung cancer worldwide (2), with the majority of patients presenting with progressive disease. Platinum-based chemotherapy remains the standard first-line treatment for advanced NSCLC (3). The identification of activating driver mutations in the epidermal growth factor receptor (EGFR) has changed the course of therapy for patients with NSCLC harboring these mutations $(4,5)$. As second-line treatment, docetaxel, pemetrexed and erlotinib exhibit low objective response rates (ORR) and short progression-free survival (PFS) (6-8). The use of immune checkpoint inhibitors such as nivolumab and pembrolizumab may prolong overall survival (OS) and duration of response in patients with NSCLC, particularly for those who express programmed death ligand-1 (PD-L1) (9-11).

At present, there are no guidelines for the systemic treatment for patients with NSCLC who have failed 2 therapy regimens. In a previous retrospective study, although a number of patients received third-line treatment, the results of salvage treatment were not satisfactory (12). With additional first- and second-line therapies being made available, the number of patients with NSCLC who are candidates for third-line, or continuing, treatments has increased during the previous decade. Therefore, an effective treatment approach is urgently required, particularly for patients with neither targetable molecular aberrations nor PD-L1 expressions.

Bevacizumab is a monoclonal antibody that targets vascular endothelial growth factor (13), and has been demonstrated to be effective when used in tandem with a number of chemotherapeutic agents for the treatment of patients with NSCLC (14-16). A combination of carboplatin, paclitaxel and bevacizumab has been approved by the United States of 
America Food and Drug Administration as a first-line treatment for advanced NSCLC due to the results of the Eastern Cooperative Oncology Group (ECOG) 4599 study (14). A combination of cisplatin, gemcitabine and bevacizumab or carboplatin, pemetrexed and bevacizumab has also exhibited encouraging efficacy as a first-line treatment $(15,16)$.

Several studies have also evaluated using bevacizumab as an adjunct to salvage treatments: One phase II study evaluated pemetrexed plus bevacizumab as second-line treatment for patients with NSCLC, and demonstrated a disease control rate (DCR) of $50.0 \%$, a median PFS of 4.0 months and a median OS of 8.6 months (17). An additional retrospective study identified the efficacy of weekly paclitaxel and bevacizumab as a fourth-line, and continuing, treatment for patients with NSCLC (18).

The combination of chemotherapy and bevacizumab as a third-line, or continuing, treatments in NSCLC has not been studied, and its efficacy remains unclear. For patients who have not received bevacizumab previously, the combination of bevacizumab and chemotherapy may be an effective salvage treatment based on encouraging antitumor activity observed as a first-line treatment (14-16). Therefore, the present study was designed to compare the efficacy and safety of chemotherapy plus bevacizumab (chemotherapy-bevacizumab group) with chemotherapy alone (chemotherapy-alone group) as a third-line, or continuing, treatment for patients with NSCLC using propensity score matching (PSM).

\section{Materials and methods}

Patients. The present retrospective analysis of 165 patients with stage IV NSCLC, diagnosed according to the 7th edition of American Joint Committee on Cancer staging system (19), who had received single-agent chemotherapy with or without bevacizumab following the failure of $\geq 2$ prior standard systemic regimens was performed at the Department of Thoracic Oncology, West China Hospital (Chengdu, China) between January 2011 and June 2016. Inclusion criteria of patients were: $>18$ years of age, ECOG performance status of 0-1 $(20,21)$, measurable lesions as defined by Response Evaluated Criteria in Solid Tumors (RECIST; version 1.1) (22), and histological or cytological confirmation of adenocarcinoma, or squamous cell and adenosquamous carcinoma but without a central lesion or lesion abutting major blood vessels, history of hemoptysis or presence of cavitation and concomitant use of full-dose anticoagulants. Patients who had previously received bevacizumab were not eligible. All patients enrolled underwent computed tomography scanning. Baseline clinical characteristics included age, sex, smoking history, histology, EGFR mutation status, number of prior regimens and type of chemotherapy regimen.

Treatment.All patients had received single-agentchemotherapy with or without bevacizumab. Single-agent chemotherapy included gemcitabine (days 1 and $8,1,000 \mathrm{mg} / \mathrm{m}^{2}$ ), pemetrexed (day 1, $500 \mathrm{mg} / \mathrm{m}^{2}$ ), paclitaxel (day 1, $150 \mathrm{mg} / \mathrm{m}^{2}$ ) and docetaxel (day $1,75 \mathrm{mg} / \mathrm{m}^{2}$ ). Bevacizumab (Avastin ${ }^{\circledR}$; Roche Diagnostics GmbH, Mannheim, Germany) was administered intravenously at a dose of $7.5 \mathrm{mg} / \mathrm{kg}$ on day 1 . Combined and monotherapy were repeated every 3 weeks and continued until disease progression or development of unacceptable toxicity.
Evaluation of efficacy, survival and toxicity. Efficacy evaluation was performed every 6 weeks following the administration of treatment. The treatment response was assessed with RECIST 1.1 as follows: Complete response (CR); partial response (PR); stable disease (SD); and progressive disease (PD). The ORR included CR and PR. The DCR included CR, PR and SD. OS was measured from the first day of chemotherapy-bevacizumab or chemotherapy alone to the day of mortality or last follow-up. PFS was defined as the time between the initiation of treatment and disease progression or mortality from any cause. The adverse events (AEs) of treatment were graded the by National Cancer Institute Common Terminology Criteria for Adverse Events (version 4.0) (23).

Statistical analysis. All statistical analyses were performed using SPSS (version 20.0; IBM Corp., Armonk, NY, USA). To minimize the effects of potential confounding factors between the chemotherapy-bevacizumab and chemotherapy-alone groups, PSM was performed. Associations between the treatment and baseline clinical characteristics were analyzed by Pearson's $\chi^{2}$ tests. Patients who had received chemotherapy plus bevacizumab were matched 1:1 with patients who had received chemotherapy alone using PSM based on the variables that were significantly different between the two groups. Propensity scores were generated by using a multivariate logistic regression (24). Patients were considered a match if the absolute difference in their propensity scores was $\leq 0.02$.

In the matched dataset, tumor responses and AEs were compared using Pearson's $\chi^{2}$ and Fisher's exact tests. Survival curves were compared using the Kaplan-Meier method using the log-rank test. Univariate and multivariate Cox proportional hazards regression were used to evaluate the prognostic factors and to calculate hazard ratios (HRs) and 95\% confidence intervals (CI) for OS and PFS. Subgroup analyses of OS and PFS were also performed by the Kaplan-Meier method using the log-rank test. All clinical variables were included in the multivariate regressions, regardless of their univariate significance level. Two-sided $\mathrm{P}<0.05$ were considered to indicate a statistically significant difference.

\section{Results}

Patient characteristics and treatment. From January 2011 to June 2016, a total of 165 patients who had received chemotherapy plus bevacizumab $(n=43)$ or chemotherapy alone $(n=122)$ as third-line, or continuing treatments were initially enrolled in the present study. For PSM-matched variables, the number of prior regimens $(\mathrm{P}=0.009)$ and type of chemotherapy regimen $(\mathrm{P}<0.001)$ were significantly different between the two groups. A total of 38 patients in the chemotherapy-bevacizumab group were then matched to 38 patients in the chemotherapy-alone group. The cut-off day of the present study was December 2016, and the median follow-up of all patients was 7.9 months (range, 1.1-62.9 months).

The baseline clinical characteristics for patients preand post-PSM are summarized in Table I. The median age of patients was 52 years (range, 40-71 years) in the chemotherapy-bevacizumab group and 49 years (range, 38-76 years) in the chemotherapy-alone group. In the chemotherapy-bevacizumab group, $34(34 / 38 ; 89.5 \%)$ comprised 
Table I. Baseline clinical characteristics for patients in the chemotherapy-bevacizumab group vs. chemotherapy alone group prior and subsequent to propensity score matching.

A, Unmatched dataset

\begin{tabular}{|c|c|c|c|}
\hline Characteristics & Chemotherapy-bevacizumab $(n=43)$ & Chemotherapy alone $(n=122)$ & P-value \\
\hline Age, years & & & 0.844 \\
\hline Median (range) & $52(37-72)$ & $56(27-76)$ & \\
\hline$\leq 60$ & 32 & 88 & \\
\hline$>60$ & 11 & 34 & \\
\hline Sex, $n$ & & & 0.287 \\
\hline Male & 19 & 67 & \\
\hline Female & 24 & 55 & \\
\hline Smoking history, $\mathrm{n}$ & & & 0.583 \\
\hline Current/previous & 14 & 47 & \\
\hline Never & 29 & 75 & \\
\hline Histology, n & & & 0.800 \\
\hline Adenocarcinoma & 38 & 105 & \\
\hline $\begin{array}{l}\text { Squamous cell/ } \\
\text { adenosquamous carcinoma }\end{array}$ & 5 & 17 & \\
\hline EGFR mutation status & & & 0.716 \\
\hline Mutant type $^{\mathrm{a}}$ & 17 & 44 & \\
\hline Wild-type/unknown & 26 & 78 & \\
\hline Number of prior regimens ${ }^{b}, n$ & & & 0.009 \\
\hline Median (range) & $3(2-5)$ & $2(2-5)$ & \\
\hline$\leq 3$ & 28 & 103 & \\
\hline$>3$ & 15 & 19 & \\
\hline Chemotherapy regimen, $\mathrm{n}$ & & & $<0.0001$ \\
\hline Gemcitabine & 30 & 39 & \\
\hline Pemetrexed & 5 & 31 & \\
\hline Paclitaxel & 3 & 8 & \\
\hline Docetaxel & 5 & 44 & \\
\hline
\end{tabular}

B, Matched (1:1) dataset

\begin{tabular}{|c|c|c|c|}
\hline Characteristics & Chemotherapy-bevacizumab $(n=38)$ & Chemotherapy alone $(\mathrm{n}=38)$ & P-value \\
\hline Age, years & & & 1.000 \\
\hline Median (range) & $52(40-71)$ & $49(38-76)$ & \\
\hline$\leq 60$ & 30 & 31 & \\
\hline$>60$ & 8 & & \\
\hline Sex & & & 0.492 \\
\hline Male & 17 & 21 & \\
\hline Female & 21 & 17 & \\
\hline Smoking history, $\mathrm{n}$ & & & 0.240 \\
\hline Current/previous & 26 & 20 & \\
\hline Never & 12 & 18 & \\
\hline Histology, $\mathrm{n}$ & & & 1.000 \\
\hline Adenocarcinoma & 34 & 35 & \\
\hline $\begin{array}{l}\text { Squamous cell/ } \\
\text { adenosquamous carcinoma }\end{array}$ & 4 & 3 & \\
\hline EGFR mutation status & & & 0.641 \\
\hline Mutant type $^{\mathrm{a}}$ & 17 & 14 & \\
\hline Wild-type/unknown & 21 & 24 & \\
\hline
\end{tabular}


Table I. Continued.

\begin{tabular}{lccc}
\hline Characteristics & Chemotherapy-bevacizumab $(\mathrm{n}=38)$ & Chemotherapy alone $(\mathrm{n}=38)$ & P-value \\
\hline Number of prior regimens ${ }^{\mathrm{b}}, \mathrm{n}$ & $3(2-5)$ & $3(2-4)$ & 1.000 \\
Median (range) & 28 & 28 & \\
$\leq 3$ & 10 & 10 & 1.000 \\
$>3$ & & & \\
Chemotherapy regimen, $\mathrm{n}$ & 25 & 5 & \\
Gemcitabine & 5 & 3 & \\
Pemetrexed & 3 & 5 & \\
Paclitaxel & 5 & 5 & \\
Docetaxel & 5 & & \\
\hline
\end{tabular}

EGFR, epidermal growth factor receptor. ${ }^{\mathrm{a}}$ Mutant type included the exon 19 deletion and exon 21 L858R mutations. ${ }^{\mathrm{b}}$ Prior regimens included chemotherapy, EGFR tyrosine kinase inhibitors and anaplastic lymphoma kinase inhibitors.
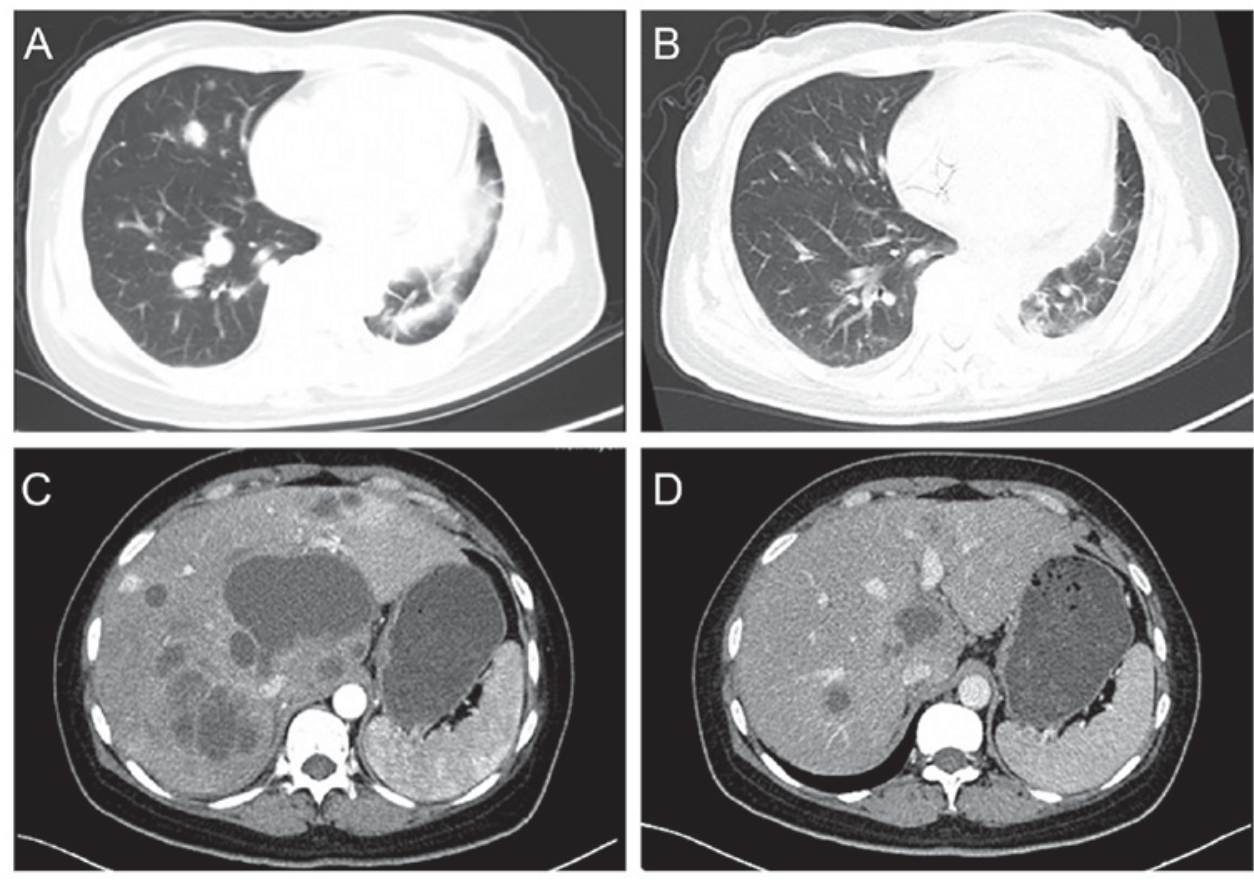

Figure 1. Examples of response to treatment with chemotherapy plus bevacizumab. CT images of a 51-year-old female with stage IV adenocarcinoma following (A) pre-treatment with chemotherapy-bevacizumab on 1st December, 2012 and (B) post-treatment with chemotherapy-bevacizumab on 6th February, 2013. CT images of a 42-year-old female with stage IV squamous cell carcinoma following (C) pre-treatment with chemotherapy plus bevacizumab on 9th May, 2015 and (D) post-treatment with chemotherapy-bevacizumab on 10th July, 2015. Images A and C were captured at baseline. Images B and D were captured following 2 cycles of chemotherapy-bevacizumab.

patients with adenocarcinoma, $2(2 / 38 ; 5.3 \%)$ with squamous cell carcinoma and $2(2 / 38 ; 5.3 \%)$ with adenosquamous carcinoma. In the chemotherapy-alone group, 35 (35/38; 92.1\%) comprised patients with adenocarcinoma, $2(2 / 38 ; 5.3 \%)$ with squamous cell carcinoma and $1(1 / 38 ; 2.6 \%)$ with adenosquamous carcinoma. The median number of prior regimens was 3 (range, 2-5) in the chemotherapy-bevacizumab group and 3 (range, 2-4) in the chemotherapy-alone group. A total of $10(10 / 38 ; 26.3 \%)$ patients had failed $>3$ prior regimens in the two groups.

The majority $(25 / 38 ; 65.8 \%)$ of patients received gemcitabine as their monotherapy or combined therapy with bevacizumab. All patients received $\geq 1$ cycle of treatment. The median number of cycles of treatment was 3 (range, 1-10) in the chemotherapy-bevacizumab group and 2 (range, 1-6) in the chemotherapy-alone group.

Tumor response. In the chemotherapy-bevacizumab group, 9 patients achieved a PR, of which 3 were squamous cell or adenosquamous carcinoma, and 16 exhibited SD, of which 1 was adenosquamous carcinoma. In the chemotherapy-alone group, 2 patients achieved a PR and 10 exhibited SD. There was a significant improvement in ORR and DCR for the chemotherapy-bevacizumab group compared with the chemotherapy-alone group (ORR, 23.7 vs. $5.3 \%$, respectively, $\mathrm{P}<0.001$; DCR, 65.8 vs. $31.6 \%$, respectively, $\mathrm{P}<0.001$ ). 
A

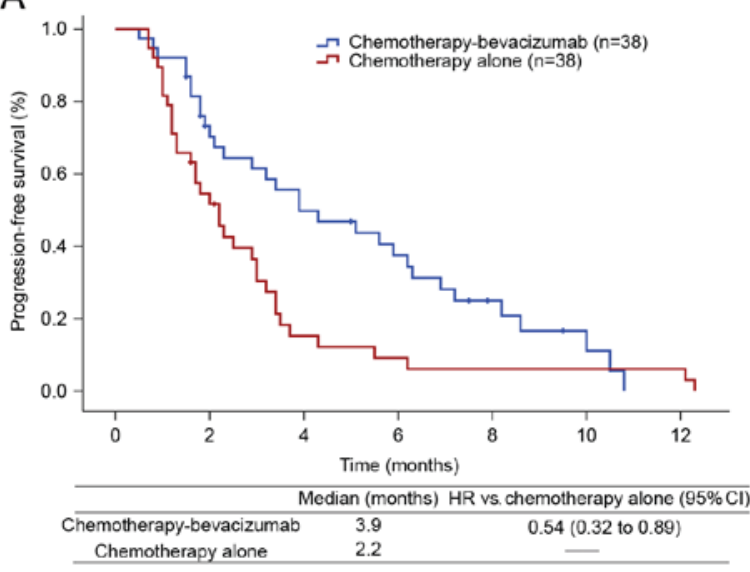

B

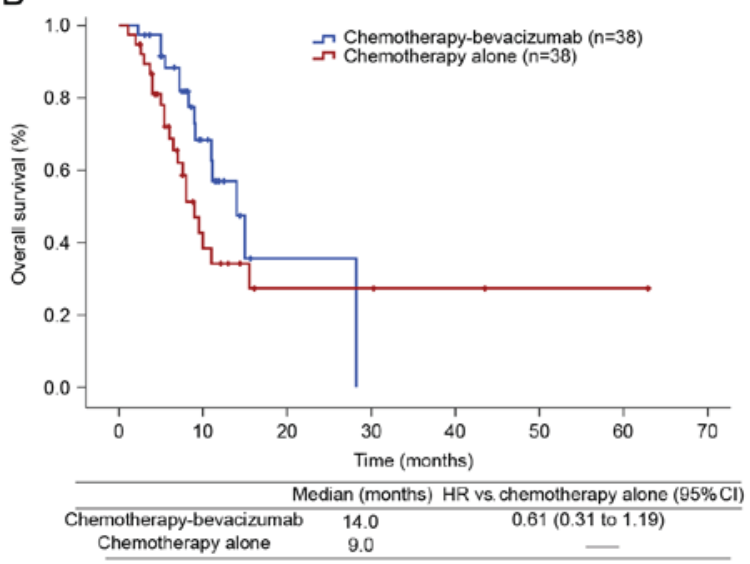

Figure 2. Kaplan-Meier survival curves from the matched dataset using (A) progression-free survival and (B) overall survival. HR, hazard ratio; CI, confidence interval.

Computed tomography scans of 2 patients with PR are shown in Fig. 1. Of these patients, 1 patient was a 51-year-old female with stage IV adenocarcinoma, who received gemcitabine plus bevacizumab as a fourth-line therapy. This patient received a total of 6 cycles of treatment, and following 2 cycles of treatment, there was a marked reduction in size of the pulmonary lesions. The PFS of the patient was 3.9 months, but she succumbed subsequent to follow-up for 9.1 months. The other patient was a 42-year-old female with stage IV squamous cell carcinoma, who received gemcitabine plus bevacizumab as a fifth-line therapy, and primarily targeted lesions in the liver. The hepatic lesions were notably reduced in size following 2 cycles of treatment. This patient exhibited a total of 10 months for PFS and survived until the cut-off point.

Survival outcome. In the univariate analysis, bevacizumab treatment was the only significant prognostic factor for PFS, but not for OS (data not shown). The duration of PFS was longer for the chemotherapy-bevacizumab group compared with the chemotherapy-alone group (median, 3.9 vs. 2.2 months, respectively; HR, 0.54; 95\% CI, 0.32-0.89; $\mathrm{P}=0.014$; Fig. 2A). The duration of OS non-significantly increased with chemotherapy-bevacizumab treatment compared with chemotherapy alone (median, 14.0 vs. 9.0, respectively; HR, 0.61; 95\% CI, 0.31-1.19; P=0.141; Fig 2B). Smoking was associated with poor OS (HR, 2.00; 95\% CI, 1.04-3.86; $\mathrm{P}=0.033)$. Multivariate analysis also demonstrated that bevacizumab treatment was the only independent prognostic factor for PFS (HR, 0.48; 95\% CI, 0.27-0.85; P=0.011; Table II), and age was the only independent risk factor for OS (HR, 4.19; 95\% CI, 1.17-14.97; P=0.027; Table II).

In the subgroup analyses, PFS was significantly prolonged following chemotherapy-bevacizumab treatment compared with chemotherapy alone in the following subgroups: Male sex; current or former smokers; adenocarcinoma subtypes; EGFR wild-type or unknown; and patients with $\leq 3$ prior regimens (Table III). PFS was notably prolonged in the subgroup of patients treated with gemcitabine (Table III). OS was significantly prolonged for chemotherapy-bevacizumab treatment compared with chemotherapy alone in the subgroup of patients with $>3$ prior regimens (Table III).
Toxicity. Hematological and non-hematological toxicities of patients in the two groups are summarized in Table IV. The incidence of severe ( $\geq$ grade 3 ) AEs was low and comparable in the two groups (chemotherapy-bevacizumab vs. chemotherapy alone, 28.9 vs. $26.3 \%$ ). In the chemotherapy-bevacizumab group, the most common AEs of all grades were leukopenia (19/38; $50.0 \%$ ), increased alanine transaminase (ALT) or aspartate transaminase (AST; 17/38; 44.8\%) and fatigue (16/38; 42.1\%). In the chemotherapy-alone group, the most common AEs of all grades were nausea $(16 / 38 ; 42.1 \%)$, leukopenia $(15 / 38 ; 39.4 \%)$ and increased ALT or AST $(14 / 38 ; 36.8 \%)$. The rates of bleeding $(\mathrm{P}=0.001)$ and hypertension $(\mathrm{P}=0.025)$ were significantly increased in the chemotherapy-bevacizumab group compared with the chemotherapy-alone group. Although 15 (15/38; 39.5\%) patients in the chemotherapy-bevacizumab group experienced grade $1 / 2$ bleeding, of which 3 were squamous cell carcinoma, there were no reports of $\geq$ grade 3 bleeding events.

Continuous bevacizumab treatment following disease progression. In the chemotherapy-bevacizumab group, 22 patients received post-progression treatment, of which 14 continued to receive bevacizumab. This treatment regimen included docetaxel plus bevacizumab in 4 patients $(4 / 14 ; 28.6 \%)$, pemetrexed plus bevacizumab in 4 patients $(4 / 14 ; 28.6 \%)$, paclitaxel plus bevacizumab in 3 patients $(3 / 14 ; 21.4 \%)$, gemcitabine plus bevacizumab in 2 patients $(2 / 14 ; 14.3 \%)$ and vinorelbine plus bevacizumab in 1 patient $(1 / 14 ; 7.1 \%)$. The median number of cycles of treatment was 2 (range, 1-4). Among the 14 patients, one patient had not received an initial evaluation of efficacy as they had not completed two cycles of treatment. Of the remaining 13 patients whose response was assessed, PR was observed in 2 patients $(2 / 13 ; 15.4 \%)$ and SD was observed in 6 patients $(6 / 13$; $46.1 \%$ ). PFS was 3.4 months (95\% CI, 2.8-4.0 months). No incident $\geq$ grade 3 AEs were observed.

\section{Discussion}

There is currently no standard systemic therapy for third-line, or continuing, treatments of NSCLC. With an increasing number of patients who meet the criteria for receiving third-line treatment or beyond, it is imperative to optimize therapy regimens 
Table II. Multivariate Cox regression analyses for progression-free survival and overall survival in patients from the matched dataset.

A, Progression-free survival

\begin{tabular}{|c|c|c|}
\hline Variables & HR $(95 \% \mathrm{CI})$ & P-value \\
\hline \multicolumn{3}{|l|}{ Groups } \\
\hline Chemotherapy-bevacizumab vs. chemotherapy alone & $0.48(0.27-0.85)$ & 0.011 \\
\hline \multicolumn{3}{|l|}{ Age, years } \\
\hline$\leq 60$ vs. $>60$ & $0.95(0.49-1.88)$ & 0.892 \\
\hline \multicolumn{3}{|l|}{ Sex } \\
\hline Female vs. male & $0.82(0.34-1.97)$ & 0.656 \\
\hline \multicolumn{3}{|l|}{ Smoking history } \\
\hline Current/previous vs. never & $1.15(0.48-2.77)$ & 0.753 \\
\hline \multicolumn{3}{|l|}{ Histology } \\
\hline Adenocarcinoma vs. squamous cell/adenosquamous carcinoma & $1.25(0.47-3.36)$ & 0.655 \\
\hline \multicolumn{3}{|l|}{ EGFR mutation status } \\
\hline Wild-type/unknown vs. mutant type & $0.74(0.41-1.36)$ & 0.333 \\
\hline \multicolumn{3}{|l|}{ Number of prior regimens } \\
\hline$\leq 3$ vs. $>3$ & $1.06(0.57-1.98)$ & 0.858 \\
\hline Chemotherapy regimen & & 0.326 \\
\hline Gemcitabine & Ref. & \\
\hline Pemetrexed & $0.50(0.21-1.24)$ & 0.137 \\
\hline Paclitaxel & $1.42(0.54-3.77)$ & 0.481 \\
\hline Docetaxel & $1.31(0.58-2.97)$ & 0.511 \\
\hline
\end{tabular}

B, Overall survival

\begin{tabular}{|c|c|c|}
\hline Variables & $\mathrm{HR}(95 \% \mathrm{CI})$ & P-value \\
\hline \multicolumn{3}{|l|}{ Group } \\
\hline Chemotherapy-bevacizumab vs. chemotherapy alone & $0.53(0.26-1.07)$ & 0.076 \\
\hline \multicolumn{3}{|l|}{ Age, years } \\
\hline$\leq 60$ vs. $>60$ & $4.19(1.17-14.97)$ & 0.027 \\
\hline \multicolumn{3}{|l|}{ Sex } \\
\hline Female vs. male & $1.30(0.36-4.74)$ & 0.694 \\
\hline \multicolumn{3}{|l|}{ Smoking history } \\
\hline Current/previous vs. never & $3.32(0.86-12.76)$ & 0.081 \\
\hline \multicolumn{3}{|l|}{ Histology } \\
\hline Adenocarcinoma vs. squamous cell/adenosquamous carcinoma & $1.33(0.29-6.11)$ & 0.711 \\
\hline \multicolumn{3}{|l|}{ EGFR mutation status } \\
\hline Wild-type/unknown vs. mutant type & $1.10(0.51-2.37)$ & 0.812 \\
\hline \multicolumn{3}{|l|}{ Number of prior regimens } \\
\hline$\leq 3$ vs. $>3$ & $1.05(0.49-2.26)$ & 0.908 \\
\hline Chemotherapy regimen & & 0.064 \\
\hline Gemcitabine & Ref. & \\
\hline Pemetrexed & $0.19(0.05-0.84)$ & 0.029 \\
\hline Paclitaxel & $0.25(0.05-1.24)$ & 0.090 \\
\hline Docetaxel & $0.57(0.21-1.57)$ & 0.275 \\
\hline
\end{tabular}

EGFR, epidermal growth factor receptor; HR, hazard ratio; CI, confidence interval; Ref, reference. 
Table III. Subgroup analyses in patients with chemotherapy-bevacizumab vs. chemotherapy alone from the matched dataset.

\begin{tabular}{lcccc}
\hline Subgroups & Median PFS (months) & Median OS (months) & HR (95\% CI) & P-value \\
\hline Male sex & 5.6 vs. 2.0 & - & $0.24(0.10-0.54)$ & $<0.0001$ \\
Current/former smokers & 4.3 vs. 2.2 & - & $0.32(0.13-0.78)$ & 0.008 \\
Adenocarcinoma & 3.9 vs. 2.2 & - & $0.59(0.35-0.99)$ & 0.037 \\
EGFR wild-type/unknown & 6.3 vs. 2.9 & - & $0.26(0.12-0.58)$ & $<0.0001$ \\
Prior regimens $\leq 3$ & 3.9 vs. 2.2 & - & $0.55(0.30-0.99)$ & 0.038 \\
Gemcitabine & 4.3 vs. 2.5 & - & $0.55-1.01)$ & $0.29(0.09-0.92)$
\end{tabular}

EGFR, epidermal growth factor receptor; PFS, progression-free survival; OS, overall survival; HR, hazard ratio; CI, confidence interval.

Table IV. Toxicity grades of patients in the two groups from the matched dataset.

\begin{tabular}{|c|c|c|c|c|}
\hline \multirow[b]{3}{*}{ Toxicity } & \multicolumn{4}{|c|}{ No. of patients $(\%)$} \\
\hline & \multicolumn{2}{|c|}{ Chemotherapy-bevacizumab $(n=38)$} & \multicolumn{2}{|c|}{ Chemotherapy alone $(n=38)$} \\
\hline & Grade $1 / 2$ & Grade $\geq 3$ & Grade 1/2 & Grade $\geq 3$ \\
\hline \multicolumn{5}{|l|}{ Hematological toxicity } \\
\hline Leukopenia & $14(36.8)$ & $5(13.2)$ & $11(28.9)$ & $4(10.5)$ \\
\hline Neutropenia & $11(28.9)$ & $3(7.9)$ & $9(23.7)$ & $4(10.5)$ \\
\hline Anemia & $15(39.5)$ & $0(0.0)$ & $12(31.6)$ & $1(2.6)$ \\
\hline Thrombocytopenia & $6(15.8)$ & $1(2.6)$ & $7(18.4)$ & $2(5.3)$ \\
\hline \multicolumn{5}{|c|}{ Non-hematological toxicity } \\
\hline Increased ALT or AST & $15(39.5)$ & $2(5.3)$ & $13(34.2)$ & $1(2.6)$ \\
\hline Fatigue & $14(36.8)$ & $2(5.3)$ & $12(31.6)$ & $0(0.0)$ \\
\hline Nausea & $12(31.6)$ & $0(0.0)$ & $15(39.5)$ & $1(2.6)$ \\
\hline Vomiting & $7(18.4)$ & $0(0.0)$ & $7(18.4)$ & $1(2.6)$ \\
\hline Rash & $4(10.5)$ & $0(0.0)$ & $3(7.9)$ & $0(0.0)$ \\
\hline Joint or muscle pain & $4(10.5)$ & $0(0.0)$ & $1(2.6)$ & $0(0.0)$ \\
\hline Hypertension & $6(15.8)$ & $0(0.0)$ & $0(0.0)$ & $0(0.0)$ \\
\hline Bleeding & $15(39.5)$ & $0(0.0)$ & $2(5.3)$ & $0(0.0)$ \\
\hline Proteinuria & $4(10.5)$ & $0(0.0)$ & $0(0.0)$ & $0(0.0)$ \\
\hline
\end{tabular}

ALT, alanine transaminase; AST, aspartate transaminase.

for eligible candidates. When combined with chemotherapy, bevacizumab has demonstrated efficacy as a first-line treatment for NSCLC (14-16), and it may also be effective as a salvage treatment for bevacizumab treatment-naïve patients with NSCLC. The present retrospective study aimed to additionally evaluate the efficacy and safety of bevacizumab in combination with chemotherapy as a third-line, or continuing, treatment for NSCLC patients. The results of the present study indicated favorable clinical outcomes with chemotherapy-bevacizumab therapy.

The values for ORR (23.7\%) and DCR (65.8\%) for the chemotherapy-bevacizumab treatment observed in the present study were higher compared with the values obtained previously, where $6.45 \%$ was reported for ORR and $54.84 \%$ was reported for DCR by Ding et al (25). Improvements in ORR and DCR in NSCLC were also noted with the chemotherapy-bevacizumab treatment in other studies $(17,26)$. Previously, ULTIMATE, a randomized, phase III study evaluated the efficacy and safety of bevacizumab as a salvage treatment for patients with NSCLC, who had previously failed first-, second- and third-line treatments and were randomized to receive weekly paclitaxel and bevacizumab or docetaxel alone. It was reported that significant improvement was observed in ORR for bevacizumab compared with docetaxel alone (22.5 vs. 5.5\%, respectively). Additionally, PFS was prolonged compared with docetaxel alone (5.4 vs. 3.9 months, respectively), but not OS (27). Similarly, in the present study, chemotherapy-bevacizumab prolonged PFS compared with chemotherapy alone (median, 3.9 vs. 2.2 months). However, improvements in PFS did not translate into significant OS benefits. This may be attributed to the enrollment of patients who had failed several regimens 
prior to receiving bevacizumab, which may have affected the OS. An additional possibility may be the small sample size in the present study, which may have reduced statistical significance between groups.

In the subgroup analyses, PFS was notably prolonged following chemotherapy-bevacizumab treatment compared with chemotherapy alone in the subgroup of patients treated with gemcitabine (median, 4.3 vs. 2.5 months; HR, 0.55; 95\% CI, 0.30-1.01). Gemcitabine may be a prognostic factor for PFS when the sample size of a study is enlarged. Additionally, gemcitabine is rarely employed as a first- or second-line treatment for patients with advanced non-squamous NSCLC (28), so it may be considered an alternative choice for salvage treatment in patients eligible to receive third-line, or continuing, treatments. The majority of patients $(25 / 38 ; 65.8 \%)$ in the present study received gemcitabine as monotherapy or combined therapy with bevacizumab, potentially informing whether gemcitabine-bevacizumab is an effective third-line, or continuing, treatment for patients with NSCLC.

The toxicity of chemotherapy-bevacizumab in the present study was well tolerated. The incidence of severe ( $\geq$ grade 3 ) AEs was low and comparable in the two groups. For AEs of all grades, hematological toxicities were commonly observed in the chemotherapy-bevacizumab group, which was also observed previously with bevacizumab (14-16,26). The high incidence of increased ALT or AST observed in the chemotherapy-bevacizumab group may be due to a high proportion of patients treated with gemcitabine. No severe bleeding events occurred, indicating that hemorrhage was managed.

Patients with squamous NSCLC have generally been excluded from studies investigating bevacizumab treatment, as squamous histology was identified as a possible risk factor for severe (grade $\geq 3$ ) pulmonary hemorrhage in a phase II study (29). However, patients with squamous histology have been enrolled in a randomized phase IIIb trial, ATLAS (30). A phase II study, BRIDGE, evaluated the safety of carboplatin, paclitaxel and bevacizumab as a first-line treatment for patients with advanced squamous NSCLC and identified that 1 patient $(1 / 31 ; 3.23 \%)$ experienced grade $\geq 3$ pulmonary hemorrhage, but no other AEs. The authors of the BRIDGE study suggested that treatment of squamous NSCLC with bevacizumab should be considered experimental (31). Based on these data, patients with squamous histology were cautiously enrolled in the present study. A total of 4 patients with squamous cell or adenosquamous histology, who received bevacizumab, did not experience grade $\geq 3$ pulmonary hemorrhage. Additionally, all of these patients responded to treatment, where 3 patients exhibited PR and 1 exhibited SD. Although the sample size was small in the present study, efficacy of bevacizumab was demonstrated in patients with squamous NSCLC.

Assessment of the efficacy and safety of patients who were treated with bevacizumab following previous failure of the drug in the present study demonstrated that the majority of patients continued to benefit from the therapy, with an ORR of $14.3 \%$, DCR of $56.2 \%$ and PFS of 3.4 months. In patients treated with chemotherapy-bevacizumab, progressive disease may be considered a failure of chemotherapy, but not necessarily of bevacizumab. Patients whose colorectal cancer had progressed with first-line treatment with bevacizumab, but who continued to receive chemotherapy-bevacizumab treatment beyond first PD, exhibited a statistically significant improvement in survival (32). In a phase II trial which compared docetaxel and docetaxel plus bevacizumab in patients with NSCLC whose disease had progressed following first-line treatment with bevacizumab plus a platinum-based doublet, significant increases in the median PFS was observed, and a longer median OS was reported in the docetaxel plus bevacizumab group (33). To validate these data, the AvaALL trial (ClinicalTrials.gov identifier, NCT01351415) evaluated the efficacy of standard of care (SOC) with or without continuous bevacizumab treatment beyond progression in patients with NSCLC progression following first-line chemotherapy-bevacizumab treatment. Results reported in 2017 ASCO demonstrated that though there was not a significantly longer OS observed in SOC+ bevacizumab compared with SOC (median, 11.86 vs. 10.22 months, $\mathrm{P}=0.1044$ ), there were significant increases in the PFS was observed in the SOC +bevacizumab groups when patients were administered third-line SOC (median, 4.0 vs. 2.6 months, $\mathrm{P}=0.045$ ) (34).

There are several limitations in the present study. Firstly, the review was retrospective and monocentric, and the number of patients included was small. Secondly, prior regimens received by patients prior to the administration of bevacizumab in the two groups were different, which may have affected the efficacy.

In conclusion, to the best of our knowledge, this is the first retrospective study to compare the outcomes of chemotherapy-bevacizumab vs. chemotherapy alone as third-line or continuing, treatment for patients with NSCLC who were bevacizumab-treatment naïve. Treatment with chemotherapy-bevacizumab was able to improve DCR and ORR, and prolong PFS in patients with NSCLC. As the number of studies on the efficacy of chemotherapy-bevacizumab as salvage treatment is limited at present, results from the present study may provide guidance for designing treatment regimens for patients with NSCLC. However, the efficacy of chemotherapy-bevacizumab in patients with NSCLC requires additional investigation in prospective trials.

\section{Acknowledgements}

The present study was supported by the National Natural Science Foundation of China (grant no. 81672982) and the Sichuan Provincial Research Foundation for Basic Research (grant no. 2016JY0050).

\section{References}

1. Chen W, Zheng R, Baade PD, Zhang S, Zeng H, Bray F, Jemal A, Yu XQ and He J: Cancer statistics in China, 2015. CA Cancer J Clin 66: 115-132, 2016.

2. Howlader N, Noone AM, Krapcho M, Miller D, Bishop K, Kosary CL, Yu M, Ruhl J, Tatalovich Z, Mariotto A, et al: SEER cancer statistics review, 1975-2014, National cancer institute. Bethesda, MD, based on November 2016 SEER data submission, posted to the SEER web site, April, 2017.

3. Schiller JH, Harrington D, Belani CP, Langer C, Sandler A, Krook J, Zhu J and Johnson DH; Eastern Cooperative Oncology Group: Comparison of four chemotherapy regimens for advanced non-small-cell lung cancer. N Engl J Med 346: 92-98, 2002.

4. Maemondo M, Inoue A, Kobayashi K, Sugawara S, Oizumi S, Isobe H, Gemma A, Harada M, Yoshizawa H, Kinoshita I, et al: Gefitinib or chemotherapy for non-small-cell lung cancer with mutated EGFR. N Engl J Med 362: 2380-2388, 2010. 
5. Zhou C, Wu YL, Chen G, Feng J, Liu XQ, Wang C, Zhang S, Wang J, Zhou S, Ren S, et al: Erlotinib versus chemotherapy as first-line treatment for patients with advanced EGFR mutation-positive non-small-cell lung cancer (OPTIMAL, CTONG-0802): A multicentre, open-label, randomised, phase 3 study. Lancet Oncol 12: 735-742, 2011.

6. Shepherd FA, Dancey J, Ramlau R, Mattson K, Gralla R, O'Rourke M, Levitan N, Gressot L, Vincent M, Burkes R, et al: Prospective randomized trial of docetaxel versus best supportive care in patients with non-small-cell lung cancer previously treated with platinum-based chemotherapy. J Clin Oncol 18: 2095-2103, 2000.

7. Shepherd FA, Rodrigues Pereira J, Ciuleanu T, Tan EH, Hirsh V, Thongprasert S, Campos D, Maoleekoonpiroj S, Smylie M, Martins R, et al: Erlotinib in previously treated non-small-cell lung cancer. N Engl J Med 353: 123-132, 2005

8. Hanna N, Shepherd FA, Fossella FV, Pereira JR, De Marinis F, von Pawel J, Gatzemeier U, Tsao TC, Pless M, Muller T, et al: Randomized phase III trial of pemetrexed versus docetaxel in patients with non-small-cell lung cancer previously treated with chemotherapy. J Clin Oncol 22: 1589-1597, 2004.

9. Brahmer J, Reckamp KL, Baas P, Crinò L, Eberhardt WE, Poddubskaya E, Antonia S, Pluzanski A, Vokes EE, Holgado E, et al: Nivolumab versus docetaxel in advanced squamous-cell non-small-cell lung cancer. N Engl J Med 373: 123-135, 2015

10. Borghaei H, Paz-Ares L, Horn L, Spigel DR, Steins M, Ready NE, Chow LQ, Vokes EE, Felip E, Holgado E, et al: Nivolumab versus docetaxel in advanced nonsquamous non-small-cell lung cancer. N Engl J Med 373: 1627-1639, 2015.

11. Herbst RS, Baas P, Kim DW, Felip E, Pérez-Gracia JL, Han JY, Molina J, Kim JH, Arvis CD, Ahn MJ, et al: Pembrolizumab versus docetaxel for previously treated,PD-L1-positive, advanced non-small-cell lung cancer (KEYNOTE-010): A randomised controlled trial. Lancet 387: 1540-1550, 2016.

12. Song Z, Yu Y, Chen Z and Lu S: Third-line therapy for advanced non-small-cell lung cancer patients: Feasible drugs for feasible patients. Med Oncol 28 (Suppl 1): S605-S612, 2011.

13. Ferrara N, Gerber HP and LeCouter J: The biology of VEGF and its receptors. Nat Med 9: 669-676, 2003.

14. Sandler A, Gray R, Perry MC, Brahmer J, Schiller JH, Dowlati A, Lilenbaum R and Johnson DH: Paclitaxel-carboplatin alone or with bevacizumab for non-small-cell lung cancer. N Engl J Med 355: 2542-2550, 2006

15. Reck M, von Pawel J, Zatloukal P, Ramlau R, Gorbounova V, Hirsh V, Leighl N, Mezger J, Archer V, Moore N and Manegold C: Phase III trial of cisplatin plus gemcitabine with either placebo or bevacizumab as first-line therapy for nonsquamous non-small-cell lung cancer: AVAil. J Clin Oncol 27: 1227-1234, 2009.

16. Patel JD, Socinski MA, Garon EB, Reynolds CH, Spigel DR, Olsen MR, Hermann RC, Jotte RM, Beck T, Richards DA, et al: PointBreak: A randomized phase III study of pemetrexed plus carboplatin and bevacizumab followed by maintenance pemetrexed and bevacizumab versus paclitaxel plus carboplatin and bevacizumab followed by maintenance bevacizumab in patients with stage IIIB or IV nonsquamous non-small-cell lung cancer. J Clin Oncol 31: 4349-4357, 2013.

17. Adjei AA, Mandrekar SJ, Dy GK, Molina JR, Adjei AA, Gandara DR, Ziegler KL, Stella PJ, Rowland KM Jr, Schild SE and Zinner RG: Phase II trial of pemetrexed plus bevacizumab for second-line therapy of patients with advanced non-small-cell lung cancer: NCCTG and SWOG study N0426. J Clin Oncol 28: 614-619, 2010.

18. Habib S, Delourme J, Dhalluin X, Petyt G, Tacelli N, Scherpereel A, Lafitte JJ and Cortot AB: Bevacizumab and weekly paclitaxel for non-squamous non small cell lung cancer patients: A retrospective study. Lung Cancer 80: 197-202, 2013.

19. Amin MB, Edge S, Greene F, Byrd DR, Brookland RK, Washington MK, Gershenwald JE, Compton CC, Hess KR, Sullivan DC, et al (eds): AJCC cancer staging manual. Springer International Publishing, 2017.

20. Charles GZ, Marvin Schneiderman MA, Emil FI, Clyde B, Lennard GG, Bruce S, Raul O, John G, Ralph J Jr, Ulfar J, et al: Appraisal of methods for the study of chemotherapy of cancer in man: Comparative therapeutic trial of nitrogen mustard and triethylene thiophosphoramide. J Chronic Dis 11: 7-33, 1960.

21. Oken M, Creech R, Tormey D, Horton J, Davis TE, McFadden ET and Carbone PP: Toxicity and response criteria of the eastern cooperative oncology group. Am J Clin Oncol 5: 649-655, 1982 .
22. Watanabe H, Okada M, Kaji Y, Satouchi M, Sato Y, Yamabe Y, Onaya $\mathrm{H}$, Endo M, Sone M and Arai Y: New response evaluation criteria in solid tumours-revised RECIST guideline (version 1.1). Gan To Kagaku Ryoho 36: 2495-2501, 2009 (In Japanese).

23. National Cancer Institute. Common Terminology Criteria for Adverse Events v4.0 (CTCAE), 2009; available from http://ctep.cancer.gov/protocolDevelopment/electronic_applications/ctc.htm.Internet; Accessed August 6, 2010

24. D'Agostino RB Jr: Propensity score methods for bias reduction in the comparison of a treatment to a non-randomized control group. Stat Med 17: 2265-2281, 1998.

25. Ding L, Liu K, Jiang Z, Chen Q, Zhou N, Liang Y, Gao H, Hong $\mathrm{X}$ and $\mathrm{Wu} \mathrm{H}$ : The efficacy and safety of pemetrexed plus bevacizumab in previously treated patients with advanced non-squamous non-small cell lung cancer (ns-NSCLC). Tumour Biol 36: 2491-2499, 2015.

26. Zhou C, Wu YL, Chen G, Liu X, Zhu Y, Lu S, Feng J, He J, Han B, Wang J, et al: BEYOND: A randomized, double-blind, placebo-controlled, multicenter, Phase III study of first-line carboplatin/paclitaxel plus bevacizumab or placebo in chinese patients with advanced or recurrent nonsquamous non-small-cell lung cancer. J Clin Oncol 33 2197-2204, 2015.

27. Cortot AB, Audigier-Valette C, Molinier O, Le Moulec S, Barlesi $\mathrm{F}$ and Zalcman $\mathrm{G}$ : Weekly paclitaxel plus bevacizumab versus docetaxel as second or third-line treatment in advanced non-squamous non-small cell lung cancer (NSCLC): Results from the phase III study IFCT-1103 ULTIMATE. J Clin Oncol 34 (Suppl-15): 9005, 2016.

28. Scagliotti GV, Parikh P, von Pawel J, Biesma B, Vansteenkiste J, Manegold C, Serwatowski P, Gatzemeier U, Digumarti R, Zukin M, et al: Phase III study comparing cisplatin plus gemcitabine with cisplatin plus pemetrexed in chemotherapy-naive patients with advanced-stage non-small-cell lung cancer. J Clin Oncol 26: 3543-3551, 2008.

29. Johnson DH, Fehrenbacher L, Novotny WF, Herbst RS, Nemunaitis JJ, Jablons DM, Langer CJ, DeVore RF III, Gaudreault J, Damico LA, et al: Randomized phase II trial comparing bevacizumab plus carboplatin and paclitaxel with carboplatin and paclitaxel alone in previously untreated locally advanced or metastatic non-small-cell lung cancer. J Clin Oncol 22: 2184-2191, 2004.

30. Johnson BE, Kabbinavar F, Fehrenbacher L, Hainsworth J, Kasubhai S, Kressel B,Lin CY,Marsland T,Patel T,Polikoff J, et al: ATLAS: Randomized, double-blind, placebo-controlled, phase IIIB trial comparing bevacizumab therapy with or without erlotinib, after completion of chemotherapy, with bevacizumab for first-line treatment of advanced non-small-cell lung cancer. J Clin Oncol 31: 3926-3934, 2013.

31. Hainsworth JD, Fang L, Huang JE, Karlin D, Russell K, Faoro L and Azzoli C: BRIDGE: An open-label phase II trial evaluating the safety of bevacizumab + carboplatin/paclitaxel as first-line treatment for patients with advanced, previously untreated, squamous non-small cell lung cancer. J Thorac Oncol 6: 109-114, 2011.

32. GrotheyA,SugrueMM,PurdieDM,DongW,SargentD,HedrickEand Kozloff M: Bevacizumab beyond first progression is associated with prolonged overall survival in metastatic colorectal cancer: Results from a large observational cohort study (BRiTE). J Clin Oncol 26: 5326-5334, 2008

33. Takeda M, Yamanaka T, Seto T, Hayashi H, Azuma K, Okada M, Sugawara S, Daga H, Hirashima T, Yonesaka K, et al: Bevacizumab beyonddiseaseprogressionafterfirst-linetreatmentwithbevacizumab plus chemotherapy in advanced nonsquamous non-small cell lung cancer (West Japan Oncology Group 5910L): An open-label, randomized, phase 2 trial. Cancer 122: 1050-1059, 2016.

34. Bennouna J, de Castro J, Dingemans AC, Griesinger F and Grossi FLanger CJ: Efficacy and safety results from AvaALL: An open-label, randomized phase III trial of standard of care (SOC) with or without continuous bevacizumab (Bev) treatment beyond progression (PD) in patients (pts) with advanced non-small cell lung cancer (NSCLC) progressing after first-line Bev and chemotherapy (chemo). J Clin Oncol 35 (Suppl 15): 9004, 2017.

This work is licensed under a Creative Commons Attribution-NonCommercial-NoDerivatives 4.0 International (CC BY-NC-ND 4.0) License. 